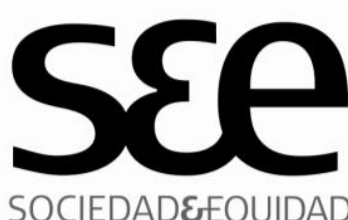

SOCIEDADEEQUIDAD

\title{
Memoria urbana, paisaje barrial e industrialización en Córdoba
}

\author{
Urban Memory, neighborhood landscape and \\ industrialization in Cordoba
}

Nombre:

Filiación:

País:

Correo:

\author{
Graciela María Tedesco ${ }^{(1)}$ \\ Universidad Nacional de Córdoba \\ Argentina \\ gramtedesco@gmail.com
}

\section{RESUMEN}

Este artículo propone analizar sentidos espaciales y memorias sobre el proceso de industrialización y urbanización en Córdoba (Argentina) entre las décadas del 50 y 60. Para ello se retoma un trabajo etnográfico realizado en barrio Santa Isabel, lugar de la ciudad de Córdoba donde se emplazó en 1955 una fábrica automotriz al calor del impulso industrial metal-mecánico en nuestro país. El análisis sobre este barrio pone en discusión los estudios que presuponen al periodo de industrialización y urbanización como un tiempo de transformación y expansión, sin detenerse en las experiencias y subjetividades de los habitantes de la ciudad ni en las agencias puestas en juego. De esta manera y procurando una mirada cercana a esas experiencias, se analizan a lo largo del trabajo registros del archivo del centro vecinal de barrio Santa Isabel sobre las actividades y reclamos vecinales en esas décadas, así como narrativas de los vecinos sobre ese momento. El artículo muestra así la relevancia de poder comprender los procesos históricos a través de espacios y temporalidades locales, a fin de penetrar en los entramados que sostienen dichos procesos y las maneras en que el pasado produce sentido y se construye en el presente.

\section{PALABRAS CLAVES}

Memoria, barrio, industrialización, urbanización, paisaje.

\footnotetext{
${ }^{1}$ La autora es parte del equipo de investigadores del Museo de Antropología, Universidad Nacional de Córdoba (Argentina). Doctora en Ciencias Sociales (IDES/UNGS) y Magíster en Antropología (FFyH-UNC). Sus líneas investigativas son: Memorias, violencias, espacio-tiempo urbano.
} 


\section{ABSTRACT}

This article proposes to analyze spatial senses and memories regarding the process of industrialization and urbanization in Cordoba (Argentina) between the decades of the 50 's and the 60's. The analysis is based on ethnographic work conducted in the Santa Isabel neighborhood, a site of the city of Cordoba where in 1955 a car factory was placed, in the heat of the metal-mechanical industry momentum in our country. The analysis of this area raises questions about studies that assume the period of industrialization and urbanization as a time of transformation and growth, without paying attention to the experiences and subjectivities of the inhabitants of the city or the agency at stake. In order to take a close look at those experiences, the paper discusses file records of the neighborhood community center Santa Isabel on the activities and neighborhood complaints in those decades, as well as narratives of the neighbors about that time. The paper shows the relevance of understanding the historical processes through local spaces and temporalities, in order to penetrate the networks that support these processes and the ways in which the past is constructed and produces meaning in the present.

\section{KEYWORDS}

Memory, neighbourhood, industrialization, urbanization, landscape.

\section{Industrialización y paisaje barrial}

La mirada sobre el proceso de industrialización ocurrido en Córdoba (Argentina) en las décadas del 50 y 60 , suele estar dirigida hacia los cambios a nivel económico y demográfico acontecidos por la implantación de fábricas e industrias metalmecánicas, así como hacia las transformaciones en el espacio urbano ocurridas en dicha época ${ }^{2}$. De este modo, industrialización y urbanización parecerían intrínsecamente vinculadas y comprendidas en un mismo movimiento. Si bien esto presenta formas heterogéneas en los distintos países Latinoamericanos, conlleva al

\footnotetext{
${ }^{2}$ Montenegro et al (2000: 7) indican que la llegada y desarrollo de las fábricas automotrices IAME, DINFIA, FIAT -con sus plantas Concord y Materferd y luego Grandes Motores Diesel-, IKA, PERKINS, CONARG, etc. le dieron a Córdoba un importante perfil industrial, produciendo un cambio social y demográfico significativo. Así, "entre 1947 y 1970, más del 50\% del incremento poblacional en la ciudad de Córdoba fue fundamentalmente consecuencia de la migración producida por la expansión de la industria metal mecánica"). En concordancia con esto, Dadone (1973/74) señala que el proceso de urbanización se acelera a partir de la década del 50 cuando la industria metal-mecánica, con su fuerte capacidad de absorción de mano de obra calificada, capital y tecnología arrastró tras de sí un gran número de industrias menores, de tipo casi artesanal, que llegó a captar casi el 40\% del incremento en la ocupación industrial del país entre 1954 y 1964. Por su parte Malecki (2010:35) también sugiere que "entre 1947 y 1960 la ciudad prácticamente duplica su población, pasando de 380.000 habitantes a más de 590.000 , superando el $30 \%$ de crecimiento. La población de Córdoba tenía una amplia mayoría de gente joven y de migrantes del interior provincial"
} 


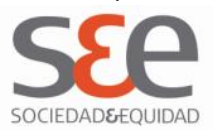

mismo tiempo puntos de encuentro y vínculos. En este sentido, a partir de la década del 40 y 50 en las ciudades latinoamericanas se producen los mayores índices de crecimiento poblacional y desarrollo urbano. Para la década de 1960 aproximadamente el $60 \%$ de la población en Argentina vivía en ciudades de más de 20 mil habitantes, el $48 \%$ lo hacía en Chile, el $40 \%$ en Uruguay y el $26 \%$ en Brasil (Schwartzman, 1966). Dichos porcentajes nunca dejaron de crecer en América Latina, alcanzando en la actualidad dicha región una urbanización del 75,3\% (Lattes, 2000). Por otra parte, en esas décadas se incrementan en la región estudios y teorizaciones que tienen por objeto el fenómeno urbano ${ }^{3}$. Estas cuestiones nos invitan a reflexionar sobre procesos más amplios y transversales, sin descuidar la mirada detallada y profunda sobre las singularidades en el contexto local (Córdoba).

A partir de la década del 50 el paisaje de la ciudad de Córdoba se vio modificado por la instalación de fábricas extranjeras que avistaron en nuestro país la potencialidad del mercado latinoamericano. Las políticas estatales favorecieron el desarrollo de la actividad industrial metal-mecánica ${ }^{4}$, atrayendo a empresas y a miles de personas del interior provincial y de otras provincias que buscaron emplearse en las mismas. Sin embargo, esto no siempre fue acompañado con políticas urbanas que amortiguaran los cambios producidos por el incremento de la población.

En este contexto, se retoman aquí algunas cuestiones halladas durante el trabajo de campo que realicé en barrio Santa Isabel durante los años 2008 y 2009, mediante el cual buscaba indagar en las memorias de sus vecinos sobre el pasado reciente. Si bien al llegar al barrio había pretendido explorar las experiencias vinculadas a la violencia en los ${ }^{7} 70^{5}$, en las primeras charlas advertí que el interés de los vecinos estaba centrado en relatar una época anterior, de impulso industrial. Al

\footnotetext{
3 Según Mesa Sánchez (1985), en la década del 50 se presentan los trabajos con una alta influencia del enfoque estructuralista de la CEPAL, con un predominio en el análisis urbano de la teoría de la marginalidad. Para la década del 60 aparece una conceptualización diferente sobre la urbanización que comienza a ser considerada como una forma hacia la "modernización", es decir, un proceso de cambio necesario para el desarrollo. En la década del 70, aparecen investigaciones desde la óptica de la teoría de la dependencia, en donde se cuestionan las teorías desarrollistas de los planes estatales y se atacan las versiones funcionalistas de la marginalidad.

${ }^{4}$ Las políticas de industrialización implicaron facilidades impositivas y crediticias. En Córdoba particularmente esto fue acompañado con la existencia de un ente estatal: Industrias Aeronáuticas y Mecánicas del Estado (IAME), que brindó mano de obra capacitada y asistencia técnica a las empresas que se asentaron en nuestra ciudad. Creada en 1952 en el predio de la escuela de aviación, IAME congregó una serie de fábricas dependientes del Estado encargadas de la fabricación de aeronaves y automóviles.

${ }^{5}$ En esta década la violencia política se exacerba con el accionar de agrupaciones guerrilleras de izquierda (Fuerzas Armadas de Liberación (FAL), Partido Comunista Revolucionario (PCR), Vanguardia Comunista (VC), Ejército Revolucionario del Pueblo (ERP), Montoneros, etc) y la aparición de grupos de ultraderecha que desarrollaron acciones terroristas. Asimismo, el 24 de marzo de 1976 un golpe de estado cívico-militar da comienzo a la Dictadura más sangrienta atravesada por nuestro país, que se extendió hasta 1982 y produjo la desaparición y muerte de miles de personas.
} 


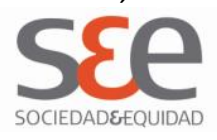

buscar información sobre los orígenes del barrio, encontré que sus primeros habitantes no pudieron imaginarse su destino fabril posterior, en tanto que el loteo del barrio fue declarado y comercializado en sus inicios como "residencial". Así, al comenzar la década del 50 la familia Nores Martínez solicitó al municipio autorización para lotear parte de las tierras de la estancia familiar, ubicada hacia el sur de la ciudad. Estas tierras habían sido compradas a finales del XIX por Rogelio Martínez, un próspero comerciante de nuestra ciudad y fundador de la bolsa de comercio de Córdoba. Al morir éste, su hija Isabel Martínez Berrotarán las adquirió, para luego ser heredadas por su esposo Antonio Nores y sus hijos, quienes decidieron lotearlas. Dicho loteo fue proyectado como un barrio de categoría, que tendría el nombre de "Residencial Santa Isabel". No obstante, a comienzos de 1955 el consentimiento de la familia Nores Martínez para instalar una fábrica automotriz en este lugar, trastocaría para siempre dicho proyecto. Al analizar el espacio presente y recapitular en la trayectoria barrial, se evidencia que si bien la fábrica transformó el espacio del barrio, ella a su vez debió someterse y adaptarse a condiciones materiales previas, combinando este lugar elementos y experiencias residenciales, rurales e industriales.

En relación a esto, Halbwachs (2004) señala que la imagen del entorno forma parte de la imagen de sí mismo que tiene un grupo. Cada detalle del lugar tiene un sentido que sólo pueden comprender sus miembros, porque todas las partes del espacio que ha ocupado corresponden a aspectos distintos de la estructura y la vida de su sociedad. De este modo, reflexionar sobre la forma en que los espacios actúan como marcos en los que se construyen memorias, nos invita a explorar los sentidos que los mismos tienen para quienes los habitan. El concepto de paisaje imaginario puede ayudarnos a abordar esta cuestión. Para Karl Schlögel (2007) los paisajes imaginarios se llevan en la cabeza, dejan huellas, imágenes, olores o recuerdos. Estas representaciones de los lugares, dice el autor, no están impresos en ninguna parte, pero se han grabado hondo y para quien los conserva, son "imborrables". "En cierta medida los mapas que se llevan en la cabeza son el mundo que uno se lleva consigo de un sitio a otro, el alimentador y procesador de imágenes" (2007: 240). Se advierte entonces relaciones profundas entre espacios y memorias, que entrañan observar las transformaciones y continuidades en la materialidad barrial y las representaciones en torno a las mismas.

Me propongo de esta manera reflexionar sobre los cambios y permanencias implicadas en el proceso industrial y urbano de mediados del siglo XX en Córdoba, a partir del análisis de un espacio barrial y de las experiencias y memorias de quienes vivieron dicha época. Pretendo de este modo analizar la combinación de materialidades y paisajes barriales en la búsqueda de ampliar la comprensión acerca de cómo ciertos procesos urbanos son construidos por las memorias, tornándose presente. Para ello analizo en primer lugar las memorias de los vecinos de Santa Isabel sobre los comienzos de la urbanización barrial y la llegada de la fábrica, las cuales se apoyan en ciertas materialidades. Adopto para ello la perspectiva de Schlögel (2007) para quien los procesos históricos pueden pensarse y describirse en 


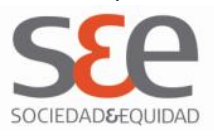

términos espaciales y locales. En segundo lugar, observo las relaciones que los vecinos tejen con grupos externos al barrio (la familia dueña de las tierras, el gobierno y la fábrica) en los primeros años de la urbanización, y las prácticas que intervinieron en la presente configuración barrial. Finalmente, reflexiono sobre la articulación entre espacios barriales y memorias para la comprensión de los sentidos otorgados a ese periodo. Los materiales utilizados en este texto retoman relatos recogidos durante el trabajo de campo, documentos del Archivo del Centro Vecinal de barrio Santa Isabel ${ }^{6}$ e imágenes (fotos aéreas) correspondientes al año 1965 halladas en la oficina de Catastro de la Municipalidad de la Ciudad de Córdoba ${ }^{7}$.

\section{Una vida “como de campo"}

En los inicios del barrio, las casas en Santa Isabel se encontraban separadas por amplios baldíos conectadas entre sí por caminitos marcados que se hacían debido al paso frecuente de las personas del lugar para acortar distancias. En este sentido, si bien mi primera intensión fue mirar la materialidad de las casas y calles como espacios a los que se enlazan memorias, a esto se fue incorporando la relevancia que tenían los recuerdos sobre los baldíos o campitos para los vecinos. Los entrevistados mencionaban la sensación de haber vivido casi en el campo o en un pueblo apartado de la ciudad, cuestión que era acentuada por el paisaje y la escasez de transporte para conectarse con el centro de la misma.

En las memorias, los campitos aparecen como el principal espacio de juego para los niños del barrio. Allí se jugaba a las bolitas, se andaba en bicicleta, se practicaba fútbol, se construían chozas y se iba “de exploración”. En relación a esto, Santino recordó que eran numerosos los niños que vivían en el barrio, hijos de los matrimonios jóvenes que se establecieron en aquel entonces. Los campitos surgen entonces como espacios que ofrecían libertad y diversión, en donde junto a otros niños se pasaba la mayor parte del día.

\footnotetext{
${ }^{6}$ El Archivo del Centro Vecinal ocupa un mueble en la biblioteca popular del barrio y contiene gran parte de las notas recibidas y producidas por el Centro desde 1951 hasta cerca del 2000. Tiempo antes de mi ingreso al campo, una estudiante universitaria en el marco de un proyecto de extensión había recuperado y organizado por año estos documentos, aunque sin darles un orden cronológico por meses y días. Debido a esto, me ofrecí a continuar esa labor y colocar las notas en folios y carpetas. Esto facilitaría mi consulta y la de futuros interesados, y me daba una ocupación concreta en mis visitas al barrio, de forma paralela a la realización de las entrevistas. Organicé así siete carpetas de archivo con notas desde 1951 hasta 1990 y tres cajas archivadoras con las notas hasta el 2000. Este trabajo deparó el descubrimiento de distintos actores (instituciones, municipios, empresas, vecinos) involucrados en el desarrollo del barrio; y permitió también ir reconstruyendo el paisaje del barrio en distintas épocas, las actividades y festejos barriales, los pedidos por el agua, el control de los baldíos, el arreglo de las calles, etc.

7 La oficina de Catastro de la municipalidad de Córdoba resguarda entre otras cosas numerosas imágenes de vuelos aéreos periódicos sobre la ciudad, el primer conjunto de los cuales data de 1965.
} 


\section{sse}

Yo volvía a mi casa tarde, después de que había jugado a las escondidas y prendido fuego a los campitos porque era como un pueblo en realidad. (...) Aparte, en esa época que venía mucha gente, había muchos chicos, por tres cuadras ya tenías una barra de chicos. Cada dos o tres cuadras ya tenías un equipito de fútbol. Y hacíamos partidos contra la barra de aquel o de aquel otro. Ahora para juntar un grupo de chicos tenés que andar 8, 10 cuadras. Ya hay mucha población anciana, muchísimos jubilados. (Santino, Marzo de 2008).

Los baldíos también aparecen en otros relatos como lugares "vacíos", espacios que no fueron ocupados por quienes los compraron o bien los abandonaron. En vinculación a esto, la lectura de las notas del Archivo del Centro Vecinal me permitió descubrir pedidos reiterados para el desmalezamiento de baldíos que aparecen como tema de preocupación porque generaban la "proliferación de víboras, ratas, acumulación de basura" o bien, dado sus altos yuyos, convertirse en escondites de "personas con malas intenciones", como explicitan las notas dirigidas a autoridades municipales.

La permanencia de sitios baldíos a lo largo de un largo tiempo tiene varias explicaciones. Algunos vecinos indican que al enterarse de que allí se iba a instalar Industrias Kaiser Argentina, empresarios de Córdoba compraron abundantes terrenos a modo de inversión y los retuvieron esperando el incremento de su precio. Manuel me señaló así:

Compraron 10, 15 lotes para negociarlos. Y ahí quedaron. Uno tenía 10, el otro 5 , el otro 5 , eran dueños ellos. Hasta que después los han vendido los lotes y recién han empezado a edificar. Y gente de Renault acá en el barrio, eran contados con los dedos. Los que vivían acá eran gente de otros barrios. Nosotros éramos todos empleados de comercio, comerciantes, los que empezamos a edificar acá (Manuel, Julio de 2009).

Por su parte Pascual, un vecino que vive en el barrio desde principios de los 60 , sugirió que muchos empleados vinieron a "probar suerte" a la fábrica, compraron un terreno y luego regresaron a sus provincias. De este modo, muchas veces no se sabía de quienes eran los lotes y no se los podía comprar nuevamente. 


\section{SEe}

Hay una tendencia a decir que el barrio se hizo por la cantidad de operarios que había. Pero no en la proporción que uno es imagina. Vino mucha gente de otras provincias esa sí intentó vivir cerca. Pero en los primeros tiempos hubo mucho movimiento porque hubo mucha gente que llegó como aventurero, no le convenció mucho, trabajó un tiempo, consiguió lo que quería y se fue. Esa gente la mayor parte, ganando bien lo primero que hacía era comprar un terreno, pero originaron un problema muy grande porque después se volvieron a Santa $\mathrm{Fe}$, a sus provincias y después teníamos muchísimo terreno desocupado y ni se sabía quienes eran los propietarios. A vos te gustaba un terreno, lo querías comprar y ni se sabía quienes eran los dueños (Pascual, Octubre de 2008).

En la siguiente imagen del archivo de catastro de la municipalidad de la ciudad de Córdoba, aparece desde una toma aérea la $1^{\text {a }}$ Sección en el año 1965. La foto permite advertir los espacios sin construcciones que predominaban en dicha época y los diferentes caminitos que se producían por el tránsito diario atravesando campitos y contorneando casas. Asimismo el foco de la imagen capta en el costado superior izquierdo a parte de la Fábrica IKA y en la parte inferior izquierda al predio del Cottolengo don Orione.

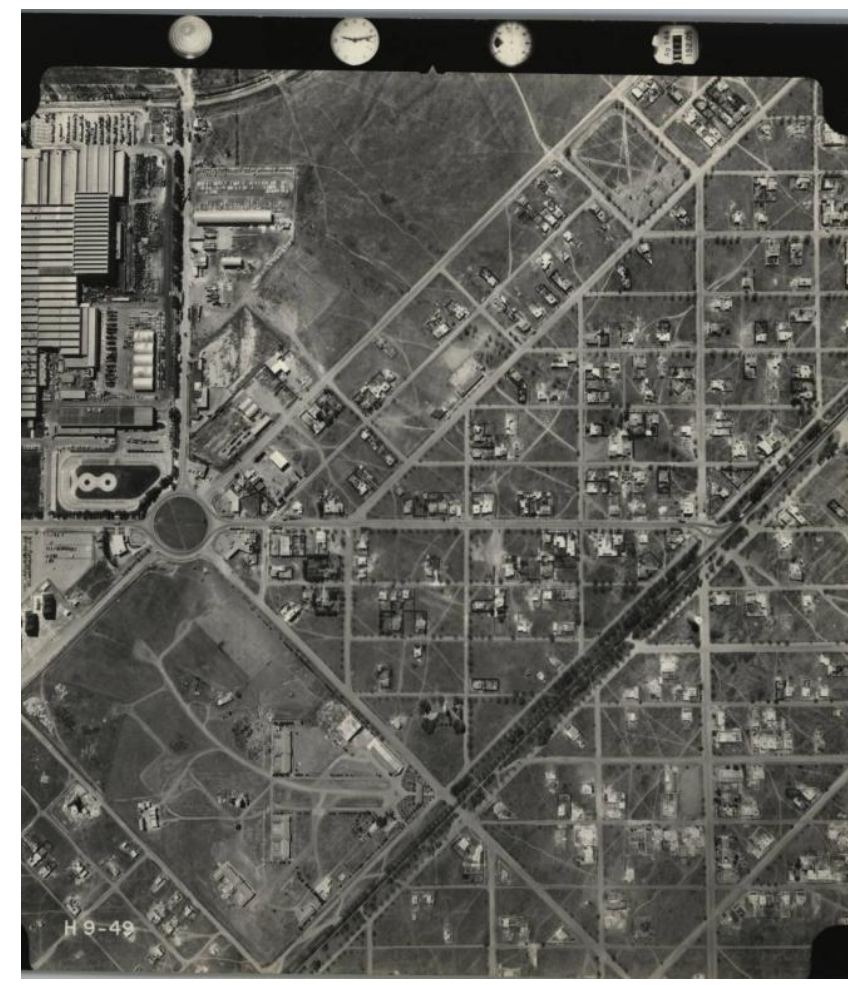

1ra Sección, año 1965. 


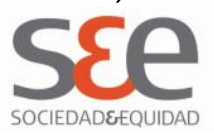

En este paisaje de amplios campitos que predominó durante varias décadas, los vecinos comenzaron a advertir que el crecimiento pronosticado al inicio del trazado del barrio y luego al instalarse la fábrica, no acontecería finalmente. Debido a esto, recuerdos ligados al progreso y al estancamiento se combinan en las memorias sobre esa época.

Compré esta casa y vinimos, nos gustó y mi marido quería vivir cerquita de Kaiser. Eso era lo que él buscaba. Y como en este momento eso estaba en crecimiento, se suponía que este barrio iba a ifa! [hace con las manos para arriba]. Que iba a explotar. Eso es lo que se supuso. Cosa que no sucedió. No sé por qué no (Maite, Octubre 2009).

Maite llegó desde Santa Fe a Córdoba en 1957 junto a su esposo, quien había sido contratado por IKA. Vivieron un tiempo en Alta Gracia y en 1959 decidieron comprar su casa en la Primera sección de Santa Isabel. Poco tiempo después, su madre, padre y hermano deciden venir también a Córdoba, siendo estos últimos contratados por IKA y construyendo también sus casas en la Primera sección. Si bien en esos años dice Maite, parecía que el barrio estaba en crecimiento, lo que ocurrió finalmente fue que se produjo una paralización.

El "crecimiento explosivo" que suele formar parte de la representación más común sobre el desarrollo industrial en Córdoba a partir de los 50, muestra aquí otras aristas. De este modo, aunque la transformación de la estructura social y urbana de la ciudad fue un hecho visible y a Córdoba llegaron importantes aportes inmigratorios, no sólo del resto del ámbito provincial sino también de otras regiones del país al observar con lente de aumento estas experiencias "en" la ciudad y en un barrio particular, se pueden descubrir matices y diversidades. Aquí los cambios como las continuidades, el crecimiento como el estancamiento, forman parte de un mismo proceso y se combinan en las memorias.

\section{Un estilo residencial...}

Aprobado en 1951, los lotes de la "futura urbanización Residencial Santa Isabel" se ofrecieron como terrenos cuyo único destino sería la vivienda. Estas casas debían tener un "estilo chalet", tal como se expresa en el Boleto de Reserva hallado en el Archivo del Centro Vecinal, con fecha 22 de mayo de 1951:

El adquirente no podrá hacer excavaciones ni pozos, ni instalaciones en los terrenos que adquiere que signifiquen una desmejora para los fines residenciales y estéticos a que se destinan a los terrenos de esta urbanización, como caballerizas, industrias o depósitos insalubres, etc. Toda 
edificación deberá hacerse teniendo en cuenta el carácter estrictamente residencial y ajustarse a estilos y tipos de chalet.

El contrato explicita el destino residencial que el adquirente debía dar a su lote e que el servicio de agua corriente y luz eléctrica estaría a cargo de la empresa urbanizadora "TAFEMAR SRL", cuyo concesionario de venta era Ernesto Tagle SA. Esta firma construyó en la esquina de las avenidas $N^{\circ} 1$ y $N^{\circ} 2$ el primer chalet del loteo y ubicó allí sus oficinas de comercialización. En torno a estas calles se comenzaron a construir las primeras casas del barrio, algunas de ellas "muy importantes" y "un lujo" según me relató Fernando, residente de este sector. Se trataban de chalets amplios con jardín delantero, techo de tejas y en algunas oportunidades revestidas con mármol, que pertenecieron a constructores e ingenieros que se establecieron en el barrio. De este modo, la Primera Sección corresponde a la parte inicial del loteo y la que posee los terrenos más amplios del barrio (alrededor de $450 \mathrm{mts} 2$ ). Compraron lotes allí inicialmente empleados de comercio, de bancos, profesionales y posteriormente empleados de la Fábrica y con otros trabajos. Como pude observar, en el presente muchos de los terrenos se han subdividido para construir las casas de los hijos de los dueños originales. Asimismo, existen en la Primera Sección diversas instituciones como el Cottolengo y el colegio Don Orione; el Centro Vecinal construido en 1960, la escuela primaria "Bandera Argentina" edificada en 1961 y el Jardín de Infantes que tuvo su edificio propio a inicios de los 80, la Biblioteca Popular "Mi Jardín" creada en 1990, el Centro de Jubilados "Bienestar para todos" fundado en 1998, la “Junta de Participación Ciudadana" en el 2001.

Al llegar la fábrica IKA en 1955, comenzó a lotearse la Segunda Sección del barrio y quienes compraron terrenos allí fueron empleados de la misma. Varios años después se impulsó la venta de lotes en la Tercera Sección, siendo adquiridos principalmente por personas que trabajaban en la construcción y operarios de menor rango en la fábrica. De este modo un desarrollo desigual y diferentes conformaciones socio-espaciales caracterizan a las secciones, cuestión que nos introduce en la heterogeneidad espacial y temporal que atraviesa a este barrio. 

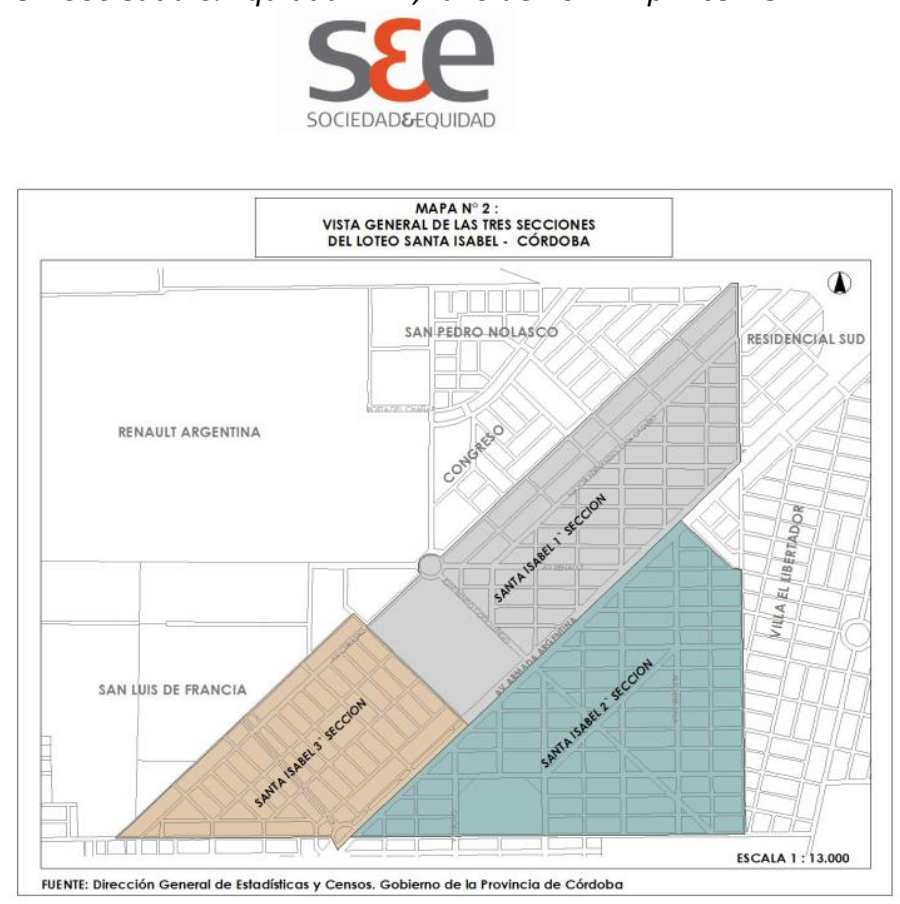

Mapa gentileza de Santiago Seppi, Licenciatura en Geografía. FFyH. UNC.

Por otra parte, la indagación sobre las representaciones en torno al espacio barrial nos invita a observar el papel que ocupan las memorias y ciertas marcas al rememorar. Como sugiere Da Costa (1999), los contextos socioespaciales y marcas físicas pueden funcionar como "auxiliares de memoria", es decir, como elementos de anclaje simbólico y relacional en los procesos de producción y transmisión de las memorias sociales y en la constitución de las identidades colectivas. De este modo, observé que había otro conjunto de casas relevantes en las memorias de los vecinos. Estas casas se construyeron en los primeros años del barrio a partir de créditos hipotecarios otorgados por el gobierno de Juan Domingo Perón. Un tipo de estos créditos era el "Plan Ordinario" que otorgaba un monto de dinero para construir la casa previa aprobación de las sucesivas etapas de construcción y estaba destinado a quienes tenían más de 5 años de aportes previsionales. El otro tipo de crédito era el "Plan Eva Perón" destinado a quienes no tenían antigüedad de aportes y que proponía tres modelos de casas estilo chalet californiano ${ }^{8}$. De este modo, trabajadores con ingresos medios podían acceder a créditos y lograr su casa propia. Así, Manuel quien trabajaba en ese momento como mozo de una confitería, me relató que solicitó un crédito ordinario y construyó su casa a comienzos de los 50 . Asimismo su hermana menor que tenía otro terreno en Santa Isabel, pidió un plan Eva Perón poco tiempo después. Muchas de las casas construidas a partir de estos planes pueden observarse a simple vista al recorrer las calles de Santa Isabel y en particular la 1ra sección. Si bien en la actualidad los techos y paredes de las mismas se

\footnotetext{
${ }^{8}$ Estilo muy difundido por aquellos años en Argentina a través de los filmes de Hollywood y adoptado como estilo de arquitectura peronista. El típico chalet californiano es una construcción compacta con techos inclinados de tejas españolas, paredes blancas, pisos de cerámica roja, galerías con arcadas, un pequeño jardín delantero y un murete de no más de medio metro de altura que separa la propiedad de la calle.
} 
encuentran algo deterioradas, son no obstante puntos de anclaje para memorias que refieren a una época de crecimiento y esplendor barrial.

Dante, quien llegó a la 1ra sección en 1956, me explicó durante una charla en su casa que luego del derrocamiento de Juan Domingo Perón en 1955 los créditos siguieron siendo otorgados debido a la buena relación existente entre los dueños de los lotes y el nuevo gobierno. Sin embargo, Dante recordaba que durante la presidencia de Frondizi (1958-1962) los créditos se paralizaron y sólo fueron liberados al ser éste depuesto y llegar los militares. Para este vecino la producción de estos golpes militares no constituyó un freno para el desarrollo barrial. Por el contrario, estas circunstancias políticas tenían un efecto contrario al que pudiera haberse previsto: "cuando cayó Frondizi, que vinieron los militares. Los militares abrieron las puertas otra vez para todos. Entonces se empezó a construir, a dar los créditos, a construir. La Segunda Sección está más habitada que la primera. La mayor cantidad de gente que vivía ahí trabajaba en la fábrica (Dante, Junio de 2009). Como se observa, Dante vincula además esta época al desarrollo que tuvo la Segunda Sección, donde con la llegada de IKA se establecieron muchos de sus empleados.

\section{La presencia industrial}

En el año 1955 el Brigadier Juan Ignacio San Martín solicitó a Antonio Nores Martínez la donación de 48 hectáreas de tierras en el sudoeste de la ciudad para la instalación de una Planta industrial para la fabricación de automóviles. Antonio Nores accedió y la firma Norteamericana Kaiser luego de evaluar las alternativas se interesó por Córdoba y estableció allí su fábrica automotriz, la primera en Argentina con tecnología de producción en serie a través de líneas de montaje.

Los breves años desde que se empezaron a vender los lotes hasta la llegada de la empresa Kaiser en 1955, sólo es recordada por los vecinos "pioneros" que cuentan hoy con una edad avanzada. En cambio quienes llegaron después, señalan que el barrio se inició al instalarse la fábrica, ya que "era un barrio para mandos medios de la fábrica" (Alfredo, Noviembre de 2009). A este respecto, indican que durante la instalación de la Fábrica vinieron a vivir al barrio varias familias "yanquis", aunque éstas luego se mudaron a "barrios mejores" que se encontraban en la zona norte de la ciudad o en localidades cercanas a Córdoba como Villa Allende o Alta Gracia, como señaló Celeste:

Cuando llega la gente de la empresa Kaiser construyen. Yo no sé si la propia empresa o la empresa loteadora, o alguien un tercero, construye muchas viviendas para supuestamente el personal jerárquico que venía. Entonces vos

\footnotetext{
${ }^{9}$ Para la instalación de la Planta se trasladaron a Córdoba alrededor de 150 empleados de las compañías de Henry Kaiser con sede en Estados Unidos. Cuando ésta comenzó a funcionar gran parte de estos ejecutivos regresaron a su país (IKA, 1965).
} 


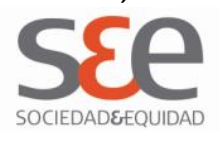

si caminás el barrio te vas a encontrar con muchas casas que ves ese tipo Californiano grande, muy importantes. Vos por ejemplo si venía por la ruta tenés lo que le llaman ahora la clínica. En su época tenía pileta de natación, no... sí... era toda... (...) ahí teóricamente era para que viviera algún personal jerárquico de la fábrica. Después hay otras casas por acá. Entrando por la avenida Renault, 4 o 5 casas de esas muy importantes. Por la calle paralela también. Son casas que se construyeron desparramadas por el barrio. Son casas muy importantes, con arboleda, jardines bien armados. Hay muchas de esas casas (Octavio, Enero 2008).

Si bien en las entrevistas aparecía de manera reiterada que "los yanquis habían construido muchos chalets en la Primera Sección", al intentar localizar el lugar donde estaban los mismos, surgieron dificultades. Las versiones eran más bien desencontradas y cuando preguntaba concretamente dónde estaban, me respondían a grandes rasgos, eludiendo direcciones o señalando que algunos de ellos habían sido "tirados abajo".

En lo que todos los vecinos coincidieron fue en la identificación de tres casas construidas sobre la actual avenida principal de la 1ra sección, que actuaron como "modelos" de las viviendas que se proponía construir y vender el sector de construcción de la Fábrica. Este proyecto finalmente no prosperó y quedaron únicamente esas tres casas originales que luego fueron alquiladas ${ }^{10}$.

Crearon un estilo muy de Estados Unidos, muy yanqui, esa era la idea de que todas las casas fueran así, iba a ser hermoso el barrio. Posiblemente iba a ser el barrio más coqueto porque iban a ser casas muy lindas e iban a quedar como un barrio residencial realmente iba a ser como un country abierto como dicen. (...) Ellos hacían esas casas y eran un estilo yanqui como esas que te mostré. Y esos chalecitos. Ese era el barrio que querían hacer ellos. Ninguna casa iba a ser así. Iban a ser todos chalets (Fernando, Agosto de 2009).

Estos chalets construidos por IKA tienen un aspecto más moderno que el de las casas construidas por los planes del gobierno peronista y se levantaron en la calle $\mathrm{N}^{\circ}$

\footnotetext{
${ }^{10}$ Brennan (1996: 56) señala que "los ejecutivos de IKA tuvieron por corto tiempo la ilusión de transformar a Córdoba en su propia versión de ciudad de la compañía, que tendría como centro el parque industrial de Santa Isabel. Con este objetivo, la empresa (...) elaboró un extenso programa para construir viviendas obrera de bajo costo, aunque este plan fue una de las primeras bajas cuando los prósperos días de fines de la década de 1950 y comienzos de la de 1960 llegaron a su fin".
} 


\section{Sce}

4 (llamada luego América del Norte y actualmente Renault) que desemboca en la rotonda frente a Kaiser. En relación a esto, cabe destacar que si al inicio del loteo la avenida $\mathrm{N}^{\circ} 2$ se consideraba la calle principal de la Primera sección, al llegar la fábrica dicha calle fue reemplazada por la avenida $N^{\circ} 4$ que comenzó a tener mayor circulación debido al ingreso y egreso de empleados y transporte. Esta calle fue hasta comienzos de los '70 la única que poseía una película de pavimento en su parte central colocada por Kaiser, lo cual permitía el paso de los camiones y ómnibus los días de lluvia.

Finalmente, otro grupo de casas que se incorporaron al paisaje barrial en los primeros tiempos del barrio, fueron las construidas por trabajadores de la fábrica. Éstos compraban en primer lugar el terreno y luego comenzaban a adquirir materiales y a construir, en la medida en que el excedente de sus sueldos (unos de más altos del país) lo permitían.

Si bien los trabajadores de la fábrica vivieron en las distintas secciones, la mayor concentración se dio al parecer en la Segunda Sección. Esta sección se encontraba separada de las otras dos como muestra la siguiente imagen, por el trazado de la ruta provincial que conduce a la localidad de Alta Gracia. Como ya señalamos esta sección comenzó a venderse poco después de instalarse la fábrica en $1955^{11}$ y tiene lotes algo menores que los de la 1ra (350 mts2 aprox.) pero mayores a los de la 3ra. A diferencia de la Primera Sección en donde muchos de los lotes fueron comprados con el fin de especular y no de habitar, en la Segunda la mayoría de quienes compraron terrenos lo hicieron para residir. Allí existe desde 1963 el Club SICA (Santa Isabel Club Atlético) fundado por una comisión integrada mayormente por trabajadores de

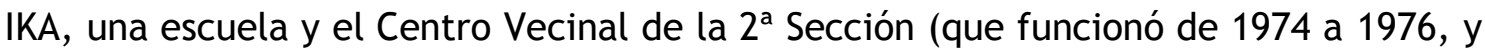
luego fue reabierto con la Democracia). De este modo, según los vecinos, la Segunda Sección fue la que más rápido se pobló y la que tiene mayor cantidad de construcciones.

\footnotetext{
${ }^{11} \mathrm{Si}$ bien el plano original que se encuentra en Catastro de la Municipalidad no tiene año, el mismo tienen señalizado la empresa IKA que llegó a Córdoba en 1955.
} 

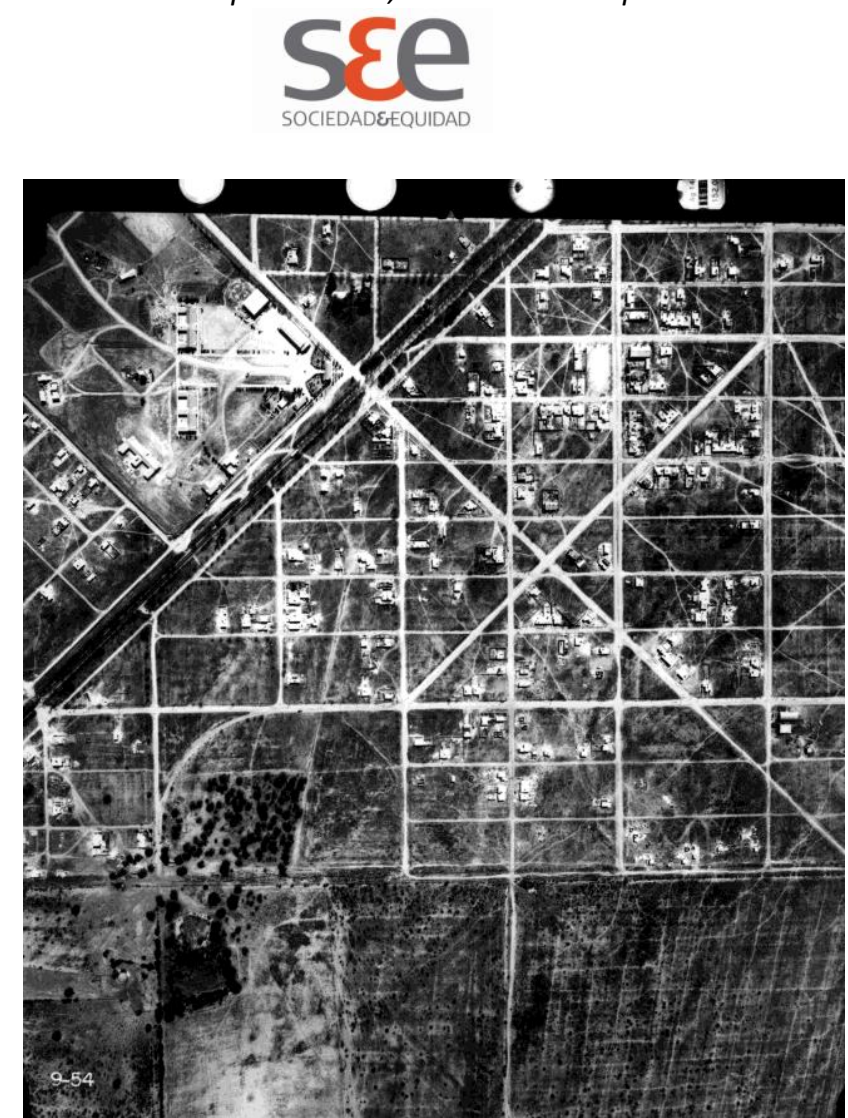

2da. Sección, año 1965.

\section{Problemas y pedidos}

En los relatos de los habitantes que llegaron a Santa Isabel por la década del 50 y 60 aparecen las numerosas dificultades que la vida barrial urbana deparaba y el intento de los vecinos por buscar soluciones ${ }^{12}$.

Se cortaba mucho la luz acá. A mí que no me digan de cortes de agua... y normalmente en el mes de enero jamás he tenido una gota de agua en el tanque. Cuando vine tuvimos que los vecinos, poner los postes, poner el cableado para poder tener la luz (Celeste, Octubre de 2008).

Baldíos poblados de yuyos, calles de tierra con polvo en suspensión los días de viento o intransitables los días de lluvia; hundimientos de tierra provocados por los mallines que existían en diferentes sectores del barrio y que dañaban los cimientos de las casas causando rajaduras; inexistencia de alumbrado público y tensión eléctrica insuficiente en las casas; agua no potable, "salada y dura", que escasea de

\footnotetext{
12 "Los problemas de la urbanización rápida parecen haberse sentido con mayor agudeza en la inadecuación de ciertos servicios públicos básicos, condiciones que eran particularmente graves en los nuevos barrios (...) Hacia fines de los años sesenta, la escasez de agua se transformó en un lugar común, con cortes frecuentes, algunos de los cuales duraban varias semanas y sistemas cloacales pobremente construidos" (Brennan, 1996: 66).
} 


\section{sse}

manera constante ${ }^{13}$... Este panorama es mostrado en las entrevistas y también en las notas que la comisión de vecinos de ese entonces escribe y dirige a la urbanizadora y a las autoridades municipales. En algunas oportunidades, los reclamos son enviados al diario, buscando hacer público pedidos que resultan sistemáticamente ignorados. En relación a esto, un recorrido por las notas del Archivo del Centro Vecinal muestra tres actores principales hacia los cuales los residentes del barrio dirigen sus pedidos y buscan obtener respuestas tendientes a mejorar las condiciones del barrio: el grupo urbanizador en el que se encuentran familias tradicionales de Córdoba, el grupo de funcionarios en el municipio y el grupo de empresarios extranjeros que ocupaba los altos cargos de la Fábrica.

En primer lugar, aparece en el archivo del centro vecinal notas de la Comisión de Vecinos del barrio hacia la empresa urbanizadora TAFEMAR solicitando principalmente mejoras en el suministro del agua. Una nota escrita en 1954 y dirigida al "presidente del Directorio de TAFEMAR", expresa el fracaso en los pedidos hacia los gerentes de la empresa, José A. Martínez Deheza y José Lucrecio Tagle (recordemos que Ernesto Tagle era el concesionario de ventas de los lotes).

Consideramos de nuestro deber que las autoridades superiores de la empresa tomen contacto directo con los problemas que pasamos a enumerar. Problemas que afectan gravemente a quienes hemos adquirido nuestras propiedades en Santa Isabel, con un gran sacrificio personal y de nuestras familias, confiados en la seriedad y garantías que ofrece una sociedad constituida por personas de reconocida solvencia moral en el ambiente (Archivo del Centro Vecinal, ACV, 28 de Febrero de 1954).

Como se advierte aquí, integran la empresa urbanizadora personas que ocupan un lugar reconocido en la sociedad cordobesa. Estos miembros de una elite tradicional como postula Juan Carlos Agulla (1968), ocupaban un rol dirigente antes de la llegada de la industrialización y ejercían un poder que representaba a su mismo estrato social.

En respuesta a esta nota, los representantes de la empresa urbanizadora escriben al Presidente de la Comisión de Vecinos:

\footnotetext{
${ }^{13} \mathrm{El}$ agua se almacenaba en una cisterna construida en la primera sección, que daba agua a tanques en las diferentes secciones, los cuales la distribuían a las distintas casas por medio de caños. Dado que los caños eran de mala calidad, se rompían continuamente y cortaban la distribución de agua. El problema recién quedó solucionado, dicen los vecinos, a principios de los 90 cuando se privatizó el servicio de agua y la empresa privada realizó una nueva conexión.
} 


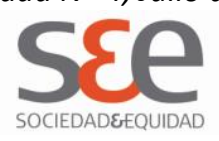

Al acusar recibo de su atenta nota (...) acompañada de un memorial relacionado con los problemas vinculados con este barrio, cúmpleme manifestarle que nuestra organización no constituye una Sociedad Anónima sino una de Responsabilidad Limitada, por lo que no cuenta con directorio alguno, siendo los gerentes los administradores legales y estatutarios de la misma y quienes ejercen la autoridad correspondiente, en atención al planteamiento formulado por dicha comisión ha elevado la nota que contesto, a la consideración de la junta consultiva que integro conjuntamente con los socios Sres. Luis Fernando Ferreyra y Dr. Felipe A. Yofre, quienes firman igualmente la presente (...).

De este modo, algunos miembros de familias tradicionales de Córdoba se encuentran mencionados en diferentes notas del archivo como encargados de la venta, trazado y urbanización del barrio. En relación a esto, un trabajo de Gabriela Cecchetto sobre esta zona de la ciudad Córdoba, señala que

(...) la ausencia total de regulación del uso del suelo en un primer momento generó una marcada actividad especulativa por parte de compañías urbanizadoras (que en muchos casos estaban integradas por los mismos dueños de las superficies que se iban subdividiendo), lo cual dio lugar a la conformación de zonas residenciales que, si bien no contaban con los servicios básicos o cubrían las exigencias legales para su habilitación, fueron rápidamente ocupadas (Cecchetto, 1990: 30).

Si bien estos nuevos barrios no reunían las condiciones mínimas para ser habitados y carecían de la infraestructura básica, poseían no obstante una población dispuesta a hacerse escuchar. Algunas notas encontradas en el Archivo del Centro Vecinal permiten advertir cierto trato de respeto y cercanía entre la Comisión barrial y el padre de la familia dueña de las tierras, Antonio Nores Martínez. A él se dirigen pedidos e invitaciones, siendo nombrado en un momento "Presidente Honorario" del Centro Vecinal (nota del 19 de Mayo de 1958).

Que velando por el progreso del barrio en que vivimos que tan dignamente lleva el nombre de su extinta esposa, esta comisión a resuelto solicitarle si tuviera dentro de sus posibilidades la donación de un pequeño trozo de terreno a los efectos de construir en el mismo el local para este centro, la estafeta de correo y el club deportivo que con el entusiasmo y esfuerzo de todos los pobladores llegará a construirse (ACV, 5 de Mayo de 1954). 


\section{SSe}

Así, Antonio Nores y su esposa Isabel Martínez se acercan a la imagen de "padres" fundadores del barrio, al punto de que actualmente sus restos mortales se encuentran sepultados en la parroquia Don Orione en Santa Isabel. En 1952 Antonio Nores donó un terreno de 15 hectáreas a la obra del Cottolengo don Orione, en el que se construyó un asilo para personas con dificultades mentales y motrices, un edificio para una escuela primaria, la parroquia de Santa Isabel y posteriormente un colegio secundario privado. Este amplio predio se encuentra en el corazón del barrio separando la 1ra. de la 3ra. Sección y frente a la 2da. Sección.

Una relación diferente, según se advierte en las notas, se produce con respecto a los hijos de este matrimonio y los socios de la compañía urbanizadora. Rogelio y Enrique Nores Martínez fueron los responsables del suministro de agua en el barrio. El carácter deficiente de este servicio y la constante falta de respuestas, conllevó a que la relación entre los mismos y los vecinos comenzara a debilitarse y tornarse tensa. Así por ejemplo, en algunas notas los cortes de agua animan a la realización de asambleas en el barrio en las que se toma la decisión de no pagar la cuota mensual de agua como medida de protesta. Estos conflictos pueden advertirse en una carta escrita por Enrique y Rogelio Nores Martínez, en respuesta a múltiples demandas de los vecinos:

Sr. Presidente de la Comisión de vecinos de Residencial Santa Isabel: Nos dirigimos a Vds. en respuesta de la nota y acta que nos cursaran (...) atento los términos perentorios de dicha comunicación, rechazamos en forma total los mismos y les hacemos saber que por ningún motivo estamos dispuestos a aceptar esta forma de dirigirse a nosotros ya que el respeto debe ser recíproco como corresponde a integrantes de una comunidad civilizada y no creer que la fuerza del número los faculta para erigirse en censores inapelables de la conducta ajena (ACV, 6 de Octubre de 1958).

Como respuesta a esto, la comisión de vecinos les dirige una extensa carta en la que señalan:

(...) que en ningún momento ha habido falta de respeto, salvo que entiendan que en lo mencionado, solicitar lo que está dentro de justicia y que hiera sus intereses; no podemos aceptar entonces, la insinuación de su párrafo “...como corresponde a integrantes de una comunidad civilizada...”, ya que allí sí notamos una falta de respeto de Uds. hacia este vecindario en gral. Tampoco pretendemos ser “...censores inapelables de la conducta ajena...”, sino por el contrario, del cumplimiento por parte de Uds. de las obligaciones contraídas, en un asunto muy delicado como la provisión de agua. De paso queremos 


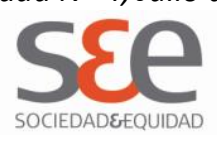

hacerles notar que la mayoría de opiniones concurrentes, cuando son atendidas se denomina Democracia (ACV, 23 de Octubre de 1958).

El convencimiento del carácter justo de sus reclamos llevó a no decaer a los vecinos en sus pedidos y reclamos. No obstante, la ausencia de soluciones implicó el tener que generar nuevas estrategias y buscar otros interlocutores, como por ejemplo personas cercanas al gobierno. Así, el 28 de abril de 1958 una nota relata nombramiento de la Sra. Victoria de Zanichelli (esposa del gobernador Arturo Zanichelli, UCR 1958 - 1960) como Presidenta Honoraria de la Sub-Comisión de damas de la Comisión de Vecinos:

Ayer tuvimos oportunidad de reunirnos con la Señora en casa de una de las Damas de la Comisión y nos ha expresado su mejor voluntad de hacer todo lo que esté a su alcance tendiente a mejorar nuestro barrio, y dotarlo de aquellos elementos que aparte de significar bienestar para sus habitantes, atrae a otros más para habitarlo. (ACV, 28 de Abril de 1958).

La ausencia de regulación en el trazado de los nuevos barrios llevó a que los vecinos llevaran sus reclamos a niveles gubernamentales. A este respecto Cecchetto observa que "el estado evita confrontar con los sectores responsables de los problemas haciéndose cargo de ellos y asumiendo compromisos que en muchos casos significan recargar al erario con obligaciones que correspondería cumplir a las empresas loteadoras" (1990: 34). En este sentido, "el gobierno municipal no cuestiona públicamente estas falencias, sino que negocia, absorbe deudas y en muchos casos legitima situaciones irregulares en nombre de la "tranquilidad pública”. El municipio resulta entonces especialmente interpelado y exigido.

Al sr. Presidente del Consejo Deliberante: La Comisión Directiva del Centro Vecinal Residencial Santa Isabel $1^{\mathrm{a}}$ sección y $2^{\mathrm{a}}$, se dirigen al Sr. Presidente del Consejo Deliberante de Córdoba a fin de solicitarle el alumbrado público para el barrio. Al mismo tiempo le hacemos notar al Sr. Presidente que nuestro barrio carece de Alumbrado Público desde su creación o sea desde el año 1952, estando a un paso de una de las más grandes fábricas del país (ACV, 15 de Julio de 1958).

Intendente Gilberto Molina. Nos dirigimos a Ud. (...) solicitándole que interponga sus recursos ante el organismo correspondiente a fin de que de estricto cumplimiento a la ordenanza que obliga al cercado y vereda a los propietarios de inmuebles (...) dada la características especial de n/barrio al 


\section{SEe}

instalarse en sus proximidades IKA, la mayor parte de los adquirentes han tenido el propósito de la especulación y por lo tanto tienen sus propiedades sin mejoras y retenidas a la espera siempre de mejores y abusivos precios con lo cual detienen n/progreso (ACV, 15 de Septiembre de 1958).

Por otra parte, junto a las notas dirigidas a la empresa urbanizadora y al municipio aparecen otras comunicaciones destinadas a la Fábrica Industrias Kaiser Argentina que evidencian una relación diferente, en las que priman pedidos de colaboración y de apoyo a la socialibilidad barrial. Se observa de este modo que en el momento más álgido de la relación con la empresa urbanizadora, se fortalece la relación con un vecino poderoso y que se recuerda "generoso": Industrias Kaiser Argentina. En este vínculo, el centro vecinal pide algo a Kaiser (por ejemplo ayuda en el arreglo de calles, donación de cosas para festejos barriales, etc) y Kaiser responde "dando", aunque sea en parte lo que se pidió.

James F. Mc. Cloud. Vicepresidente de IKA: Es con verdadera satisfacción, que nos dirigimos a Ud. y por su intermedio al Directorio de esa Cía. con el fin de invitarles a la fiesta conmemorativa del 25 de mayo que se realizará según el programa que adjuntamos preparado por la comisión vecinal de este barrio, que se ha visto favorecida por IKA, quien como generoso vecino le ayudó facilitándoles instalaciones y material para dar brillo y realce a la misma (13 de Mayo de 1958).

En otras oportunidades se le da a la empresa un lugar de mayor relevancia y quien es su gerente general es nombrado "presidente honorario" de la comisión de vecinos.

Gerente General de Industrias Kaiser Argentina S. A.: Nos es grato dirigirnos a Ud. informándole que ha sido renovada la Comisión Directiva del Centro Vecinal Residencial Santa Isabel, cuyos componentes figuran en lista adjunta y de cuya Comisión en su oportunidad Ud. tuviera a bien aceptar ser Presidente Honorario (...) Asimismo deseamos comunicarle que hemos designado como representante de nuestra comisión ante I.K.A, a nuestra secretaria Sra. Ana T. de Mur (Departamento 811 - Repuestos - IKA) a quien rogamos hacer llegar cualquier comunicado (ACV, 27 de Enero de 1959). 


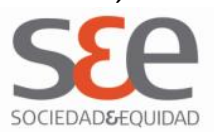

Como se observa aquí, la comunicación con la Fábrica se produce a través de diferentes vías: notas dirigidas directamente al Presidente o al Gerente de Relaciones Públicas; pedidos de audiencias al presidente de IKA para conversar sobre algún problema del barrio; mensajes a través de los miembros de la comisión directiva del Centro Vecinal que a su vez son empleados de la Planta. Como recordó Maite durante una entrevista:

Maite: (...) mi hermano como trabajaba en la Kaiser, era el que hacía las conexiones, los pedidos llamémosle para el barrio, lo mandaban mucho a mi hermano.

G: ¿Y él estaba en alguna parte de la empresa particular para que le asignaran esa tarea?

M: No, él era de la comisión del Centro Vecinal de barrio Santa Isabel. Por eso le decían "vos que estás allá, que estás con los de más arribita”. Entonces cuando él va allá y le comenta a los de Kaiser, que le iban a poner el nombre a las calles, es cuando ellos dicen "si ustedes le ponen nombres a las calles que sean todas gobernaciones norteamericanas, nosotros los vamos a ayudar un montón". Y por eso las calles se llaman como se llaman. Michigan, Texas, Arcansas, Luisiana. (...) Entonces por eso se pone el nombre. Como no costaba nada poner Martín Fierro o Michigan... (Maite, Octubre del 2009).

Maite describe así el modo en que se consigue la ayuda de IKA para la nomenclatura de las calles: la empresa donaba los carteles y el Centro Vecinal solicitaba al Municipio que las calles de la Primera Sección tuvieran nombres de gobernaciones de Estados Unidos. La Segunda Sección tendría nombres de ciudades de América del Sur ${ }^{14}$, y la Tercera de ciudades de América Central. Se producía de este modo un intercambio.

Al recordar la relación del barrio con la empresa, los vecinos remarcan la generosidad de la misma "cuando estaban los yanquis" (IKA) en contraposición al momento en que llegaron "los franceses" 15 . En este sentido, cuando años después las acciones de la empresa son compradas por Renault y pasa a ser dirigida por empresarios franceses, los recuerdos indican que la empresa deja de "dar" y se

\footnotetext{
${ }^{14}$ Actualmente la mayoría de los nombres de las calles de esta sección han cambiado, y se le han puesto los nombres de algunas calles de Villa Libertador que son continuación de las mismas.

${ }^{15}$ Entre 1955 y 1967 la fábrica estuvo dirigida por la firma norteamericana Kaiser y se llamó Industrias Kaiser Argentina. A partir de 1967, la firma francesa Renault compra parte de las acciones, y la empresa toma el nombre de IKA-Renault. En 1975 Kaiser le vende a Renault las acciones restantes y se retira de Argentina. Desde esa fecha hasta la actualidad la fábrica adopta el nombre de Renault, con excepción del periodo entre 1992 y 1997 donde se llamó CIADEA (Compañía Interamericana de Automóviles).
} 


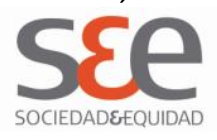

aparta del barrio. A este respecto, encuentro puntos de contacto con el estudio de trabajo de Neiburg (1988) sobre la empresa Loma Negra. Este autor marca dos épocas. Una antes de 1976, cuando el patrón vivía y se daban relaciones más personalizadas, y otra a partir de ese año, cuando el patrón muere y las relaciones con la empresa pasan a ser más impersonales ${ }^{16}$. Así, en las memorias se señala que la Fábrica brindaba algo de apoyo en la Primera y Segunda Sección, y el barrio le devolvía reconocimiento. La Tercera sección comenzó poblarse en último lugar y casi no alcanzó a experimentar esta época de la fábrica. La misma posee los terrenos más pequeños (250 mts2 aprox.) del loteo y fue ocupada principalmente cuando la empresa IKA inició la venta de sus acciones a Renault por fines de los 60 . Fue de este modo la última de las tres secciones en ser ocupada y la que en mayor medida sufrió la carencia de servicios urbanos. Así, a diferencia de las otras dos secciones que poseen casi todas sus calles asfaltadas, la mayoría de las calles de la 3ra. Sección no lo están y se observa en sus casas estructuras más simples y muchas en proceso de construcción.

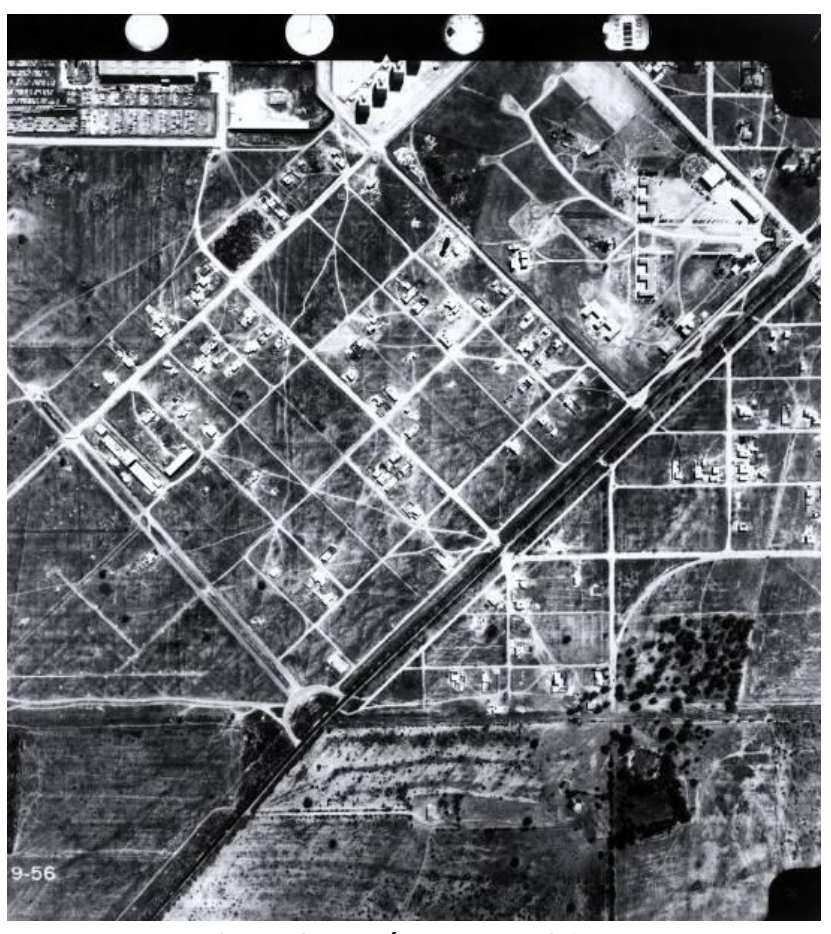

3ra. Sección, año 1965.

\footnotetext{
${ }^{16}$ Antes de 1976, se recuerda a un "patrón benefactor" con quien se tratan los problemas de modo directo y de quien se espera "beneficios". Estas ayudas y beneficios son representados como "dones libres" a cambio de los cuales quienes los reciben no deben dar nada a cambio. Sin embargo, como advierte Neiburg (1988) dado que la beneficencia es una modalidad de relación recíproca que no es percibida de este modo por el receptor, el hecho de que el donante aparezca "dando algo a cambio de nada" constituye un don que genera las mayores dependencias y ataduras.
} 
Si los problemas derivados de la rápida urbanización fue una característica de todo el barrio, éstos fueron más profundos en la Tercera Sección. El retiro de la firma IKA de su participación en la fábrica, el desentendimiento progresivo de la urbanizadora por los problemas del barrio y la carencia de recursos por parte del municipio para hacer frente a las deficiencias urbanas, generó en los 60 y comienzos de los 70 una mayor movilización de los pobladores para mejorar sus condiciones de vida. Cabe observar en este marco, que si bien casi por la misma época los reclamos sindicales cobraron gran visibilidad y relevancia ${ }^{17}$, ambos parecerían caminar por veredas diferentes. A pesar de que muchos de los obreros se encontraban viviendo en estos nuevos barrios, Brennan (1996: 66) señala que "la clase obrera cordobesa sólo hizo referencias ocasionales y al pasar a los problemas urbanos en sus protestas de fines de la década de 1960 y comienzos de la de 1970, preocupándose mucho más por los directamente relacionados con el trabajo y la política". En este sentido, reflexionar sobre cuestiones vinculadas al "habitar" y al "trabajar" pueden brindarnos indicios sobre este hecho, pero en futuras indagaciones.

\section{Llegando al final...}

Trazar un barrio y traer una industria fue, nada más ni nada menos, lo que ocurrió en Santa Isabel entre las décadas del 50 y 60 . Para comprender esta cuestión, en este trabajo ejercitamos una mirada profunda y detallada sobre dicho proceso en dicho barrio, sin desconocer las posibilidades de encontrar múltiples puntos de contacto y diálogos entre éste y otros casos similares en la región.

Se observó así que ciertas marcas espaciales actúan como anclajes en la construcción de memorias y que, combinadas con representaciones sobre paisajes barriales, complejizan los sentidos que se articulan al recordar este espacio en la ciudad. De esta manera, advertimos que si bien en el presente se encuentra en Santa Isabel una gran diversidad de estilos de casas, los vecinos otorgan un lugar privilegiado a las viviendas residenciales que se construyeron a finales de los $50 \mathrm{y}$ comienzos de los 60. Se tratan de "chalets importantes" que evocan una época de impulso y fe en el progreso del barrio. Estas "primeras casas" se convirtieron en referentes de valor estético, pero también actúan como productoras de valores y aspiraciones para los vecinos. Junto a estas viviendas, los espacios baldíos, las calles, el Cottolengo, la Fábrica, etc. ayudan a reconstruir las memorias de los vecinos y

\footnotetext{
${ }^{17}$ Así por ejemplo, el "Cordobazo" producido el 29 de mayo de 1969, fue una movilización obrera y estudiantil sin precedentes en Córdoba y en la región, que se opuso a las políticas económicas y políticas del entonces gobierno militar de Onganía. Durante el Cordobazo se enfrentaron los obreros de los sindicatos más importantes de ese momento en Córdoba, SMATA (conducido por Elpidio Torres), Luz y Fuerza (dirigido por Agustín Tosco), UTA (conducido por Atilio López) apoyados por estudiantes, contra las fuerzas policiales y militares en las calles de la ciudad.
} 


\section{SSe}

anudan experiencias vinculadas a ese momento. Por otra parte, los paisajes que rememoran los vecinos expresan la convivencia entre paisajes rurales, urbanos e industriales y la superposición de diferentes temporalidades en un mismo lugar.

De esta manera, los cambios en la ciudad pueden ser analizados no sólo al observar las "acciones" en el territorio, sino también las "inacciones y abandonos". En ellos se vieron involucrados una diversidad de actores que comenzaron a interactuar a partir de problemas y reclamos derivados de la urbanización e industrialización. En este sentido, indagar sobre procesos históricos más amplios en espacios y tiempos locales, como propone Schlögel (2007), nos conduce a penetrar en los entramados que sostienen dichos procesos y los modos en que el pasado produce sentido y es construido en el presente.

\section{Referencias Bibliográficas}

Agulla, Juan Carlos (1968). Eclipse de una aristocracia. Una investigación sobre las élites dirigentes de la ciudad de Córdoba. Buenos Aires: Ediciones Líbera.

Brennan, James (1996). El Cordobazo. Las guerras obreras en Córdoba, 1955-1976. Buenos Aires: Editorial Sudamericana.

Cecchetto, Gabriela (1990). "Evolución de los asentamientos industriales IKA y FIAT. Su inserción en el espacio urbano cordobés. Un estudio comparado (1955 - 1968)". Informe presentado a CONICOR (Consejo de Investigaciones de Córdoba). Inédito. Córdoba.

Da Costa, António (1999). Sociedade de bairro. Dinâmicas sociais da identidade cultural. Portugal: Celta Editora.

Dadone, A. (1973/74). "Cien años de industria en Córdoba". Revista de Economía, N 24. Córdoba: Banco de la Provincia de Córdoba.

Halbwachs, Maurice (2004 [1950]). La memoria colectiva. Zaragoza: Prensas Universitarias de Zaragoza.

IKA (1965). IKA 10 años. Buenos Aires: Publicaciones IKA. 
Lattes, Alfredo (2000). "Población urbana y urbanización en América Latina". Comunicación presentada en II Jornadas Iberoamericanas de Urbanismo sobre las Nuevas Tendencias de la Urbanización en América Latina, Quito, Ecuador.

Malecki, Sebastián (2009). “Intelectuales y obreros en la Córdoba de los 60-70: una aproximación a las experiencias de pasado y Presente y Sitrac-Sitram”. En Héctor Schmucler y otros, El obrerismo de pasado y presente. La Plata: Ediciones al Margen.

Mesa Sánchez, Nora Elena (1985). “Interpretación de la urbanización en América Latina". Ponencia presentada en el $10^{\circ}$ y $11^{a}$ Talleres Latinoamericanos del Programa de Estudios, Medellín, Colombia.

Montenegro Jorge (2000). Córdoba en su situación actual. Bases para un diagnóstico dirección de urbanismo. Córdoba: Municipalidad de la Ciudad de Córdoba.

Neiburg, Federico (1988). Fábrica y villa obrera: Historia social y antropología de los obreros del cemento. Buenos Aires: Centro Editor de América Latina.

Schlögel, Karl (2007). En el espacio leemos el tiempo. Sobre historia de la civilización y geopolítica. Barcelona: Siruela.

Schwartzman, Simon (1966). “Urbanización y desarrollo en Brasil”. En Jorge Hardoy y Carlos Tobar (Eds.), Vivienda para América Latina. Buenos Aires: Editorial del Instituto. 